\title{
Precision livestock feeding, principle and practice ${ }^{1}$
}

\author{
C. Pomar ${ }^{*}$, J. van Milgen† and A. Remus ${ }^{*}$ \\ *Agriculture and Agri-Food Canada, 2000 College Street, Sherbrooke, QC, Canada, J1M 1Z3, \\ $\dagger$ INRA, UMR1348 PEGASE, 16 le clos, Saint-Gilles, France,35590
}

Corresponding author: candido.pomar@canada.ca

\section{Summary points}

- $\quad$ Precision livestock farming (PLF) is proposed to the livestock industry as an essential tool to enhance sustainability and competitiveness

- $\quad$ Precision livestock feeding is part of PLF and can have a great impact in livestock profitability due the ability of feeding pigs with diets tailored daily to their nutrient requirements. - $\quad$ Precision livestock feeding can decrease livestock environmental impacts by optimizing the use of dietary nutrients and animal nutrient utilization efficiency which results in less nutrient excretion.

- $\quad$ Mathematical models developed for precision livestock feeding must be designed to operate in real-time using system measurements. These models are structurally different from traditional nutrition models.

- $\quad$ The success of PLF is dependent on the precision livestock feeding integration into the system, as well, the adaptability and training of the farmers to use PLF systems.

\begin{abstract}
Precision livestock farming (PLF) is an innovative production system approach based on intensive and integrated use of advances in animal sciences and technology of information to automatically and continuously monitor and control farm processes. The use of PLF can help farmers to improve management tasks such as monitoring of animal performance and health, and optimization of feeding strategies. An important component of PLF is precision livestock feeding, which consists in providing in real-time to individuals or group of animals with the amount of nutrients that maximizes nutrient utilization without loss of performance. The use of precision livestock feeding can decrease protein intake by $25 \%$, nitrogen excretion into the environment by $40 \%$, while increasing profitability by nearly $10 \%$. The success of the development of PLF and precision livestock feeding depends on the automatic and continuous collection of data, data processing and interpretation, and the control of farm processes. The advancement of precision livestock feeding requires the development of new nutritional concepts and mathematical models able to estimate individual animal nutrient requirements in real-time. Further advances for these technologies will require the coordination of different experts (e.g., nutritionists, researchers,

\footnotetext{
${ }^{1}$ This project was funded by Swine Innovation Porc within the Swine Cluster 2: Driving Results through Innovation research program which founds were provided by Agriculture and Agri-Food Canada through the AgriInnovation Program as well as by provincial producer organizations and industry partners. Funding was also provided by the European Union's Horizon 2020 research and innovation program under grant No. 633531.
} 
engineers, technology suppliers, economists, farmers, and consumers) and stakeholders. For the adoption of PLF and precision livestock feeding the development of integrated user-friendly systems and the end-user training is imperative. The development of PLF will not just be a question of technology, but a successful marriage between knowledge and technology in which improved and intelligent mathematical models will be essential components.

Keywords; Precision livestock farming, farm management, automatization, modern livestock production, nutrition

\section{Introduction}

Precision livestock farming (PLF) is an innovative production system approach that can be defined as the management of livestock using the principles and technologies of process engineering (Wathes et al., 2008). The intensive and integrated use of advances in animal science and in the technology of information and communication are the basis for the development of PLF. One of the objectives for developing PLF systems is the on-line continuous and automatic monitoring of animals to support farmers in the management of animal production such as feeding strategies, control of the growth rate, and health management (Berckmans, 2004). The main purpose of PLF is, however, to enhance farm profitability, efficiency, and sustainability (Banhazi et al., 2012a). Precision animal nutrition or precision livestock feeding is considered in this document as part of the PLF approach and involves the use of feeding techniques that allow the proper amount of feed with the suitable composition to be supplied in a timely manner to a group of animals (Parsons et al., 2007; Cangar et al., 2008; Niemi et al., 2010) or to individual animals in a group (Pomar et al., 2009; Andretta et al., 2014). The on-farm application of precision livestock feeding requires the design and development of measuring devices (e.g., to determine the animal's feed intake and weight), computational methods (e.g., estimating in a timely manner nutrient requirements based on the actual animal's growth), and feeding systems capable of providing the required amount and composition of feeds that will generate the desired production trajectory.

The practical application of precision livestock feeding can have great impact in livestock profitability. Feed is the most important cost component in commercial growing-finishing pig production systems and represents between 60 and $70 \%$ of the overall production costs. Similar figures hold for broilers and other livestock. Given that nutrients that are not retained by the animal or in animal products are excreted via the urine and faeces or as heat, and that the efficiency by which domestic animals transform dietary nutrients into animal products are generally low, improving the nutrient efficiency can largely contribute to reducing production costs and improve the sustainability of livestock production systems. In fact, nitrogen and phosphorous, which are among the most costly nutrients in livestock feeds, are retained with efficiency rarely greater than 35\% (Dourmad et al., 1999; Poulsen et al., 1999). The inefficiency of nitrogen and phosphorous use has different causes. First, part of these ingested nutrients are used for basal metabolic processes involving degradation (catabolism) and synthesis (anabolism), or are lost in the digestive tract through desquamation and endogenous secretions. These losses are generally referred to as maintenance losses. Nutrients are also lost during the production of animal products (e.g., body protein and lipid, milk, and eggs). In growing animals, the losses associated with the utilization of the first-limiting amino acid for body protein deposition can largely be attributed to the inevitable catabolism (Heger and Frydrych, 1985; Mohn et al., 2000). These inevitable amino acid losses should be differentiated from other metabolic losses related to the preferential amino acid catabolism, which results from the catabolism of amino acids given in excess, from the excretion 
of chemically unavailable absorbed amino acids (e.g., heat damaged proteins) (Batterham et al., 1990), and from the use of amino acids for the synthesis of non-protein body compounds (Moughan, 1989). In growing animals fed cereal-based diets, the sum of the undigested nitrogen and the losses associated with digestion, maintenance functions, and body protein deposition may represent more than $40 \%$ of the total ingested nitrogen.

Pigs, broilers, and other livestock animals are typically raised and fed in groups, usually with the same feed that is given to all animals in the group during a given period of time. However, nutrient requirements vary largely among animals in a population (Pomar et al., 2003; Brossard et al., 2009) and these requirements evolve over time following individual patterns (Hauschild et al., 2012; Andretta et al., 2014). When growth maximization is the objective of a commercial production system, nutrients have to be provided at a level that will allow the most nutrient demanding animals in the group to express their growth potential (Hauschild et al., 2010). In this situation, almost all animals receive more nutrients than they need. Providing animals with high levels of nutrients to maximize herd performance is common practice in commercial livestock operations even though maximum growth does not ensure maximum economic efficiency (Hauschild et al., 2010; Niemi et al., 2010). Besides the estimated 40\% nitrogen loss associated with digestion, maintenance, and production inefficiencies, an additional $30 \%$ loss results from protein given in excess to optimize the production response of the group. To account for the variability among animals but also among feed ingredients and other uncontrolled factors (e.g., environment, health) nutritionists include safety margins when formulating diets to ensure the maximum population responses. The need of these safety margins can be seen as an admission of our inability to precisely estimate the nutrient requirements of groups of animals (Patience, 1996).Precision nutrition will play an important role in future animal production systems because innovative monitoring approaches simplify the determination of nutrient requirements which, when estimated in real-time, allow for the possibility of feeding animals, individually or as a group, according to specific production objectives. These objectives include the maximization or the controlling of growth rate, or to minimize the excess supply of nutrients and reducing environmental impacts. Safety margins are not required in precision livestock feeding. Compared to a 3-phase feeding program for growing pigs, precision livestock feeding can reduce protein intake by $25 \%$ and reduce nitrogen excretion by almost $40 \%$ while feed cost can be reduced more than 10\% (Pomar et al., 2010). Because animals and feed distribution are monitored and controlled automatically, precision livestock feeding will reduce the time that nutritionists and farm staff will spend on animal observation, decision-making, and applying production strategies, enabling them to work on other aspects of farm management. The objective of this chapter is to describe the basic concepts of precision livestock feeding, its essential elements and illustrate practical applications of precision livestock feeding for growing and finishing pigs.

\section{The basic concepts of precision livestock feeding}

Precision animal nutrition or precision feeding concerns the use of feeding techniques that provide animals with diets tailored according to the production objectives (i.e., maximum or controlled production rates), including environmental and animal welfare issues. Precision livestock feeding is presented in this document as the practice of feeding individual animals or groups of animals while accounting for the changes in nutrient requirements that occur over time and for the variation in nutrient requirements that exists among animals. As defined in this document, the accurate determination of available nutrients in feeds and feed ingredients, precise diet formulation, and the determination of the nutrient requirements of individual animals or 
groups of animals should be included in the development of precision livestock feeding (Sifri, 1997; Van Kempen and Simmins, 1997; Pomar et al., 2009). The operation of precision livestock feeding in commercial farms requires the integration of three types of activities: 1) automatic collection of data, 2) data processing, and 3) actions concerning the control of the system (Aerts et al., 2003; Berckmans, 2004; Banhazi et al., 2012b). Application of precision livestock feeding at the individual level is only possible where measurements, data processing, and control actions can be applied to the individual animal (Wathes et al., 2008).

\section{Automatic data collection}

Measurements on the animal, the feeds and the environment are essential in precision livestock feeding and these have to be measured directly and frequently (if possible, continuously). Measurements that can be made at the animal level include feed intake (e.g., quantity eaten, feed intake behaviour), its physical state (e.g., body weight, body composition), and indicators of its behavioural and health status (e.g., physical activity, interactions among animals). The availability and the rapid development of new devices and emerging sensor technologies to PLF and precision livestock feeding, offer a great potential for animal monitoring. Available technologies and sensors have been described by Wathes et al. (2008) and include low-cost cameras which, in combination with image analysis, can be used to quantify animal behaviour and estimate body weight. Realtime sound analysis and audio-visual observations have been proposed to monitor health status and welfare in pigs (Vranken and Berckmans, 2017) and behaviour in laying hens (Berckmans, 2004; Vranken and Berckmans, 2017).

Besides the availability of technologies allowing the measurement of animal traits, some guiding principles have to be used for choosing the appropriate and relevant devices and sensors to be used in precision livestock feeding. Black and Scott (2002) used the Hazard Analysis Critical Control Point (HACCP) in the Australian "More Beef from Pastures" program. The HACCP was proposed to ensure that the most important processes determining productivity and profitability in an animal enterprise were identified and could be controlled and manipulated with the least chance of failure (Black, 2007) including the development of PLF applications (Banhazi et al., 2012b). In the context of automatic data collection for precision livestock feeding, the HACCP principles are a) to identify the factors that have quantitatively a major impact in the determination of the response of the animal or of the population to the nutrient supply, and b) for each one of these factors, determine the measurements that have to be taken at the farm or animal level to ensure the application of precision livestock feeding. At this point, precision livestock feeding developers have to avoid the temptation of looking for practical applications of currently available sensors but rather concentrate on identifying the most important physiological factors and measurements needed to establish optimal feeding strategies. These measurements have to be related to the precise evaluation of the nutritional value of the diet, the real-time determination of nutrient requirements (Pomar et al., 2009), and the responses of the animal to the nutrient supply. The application of HACCP principles to identify production hazards is not addressed further in this paper and the reader is referred to Black (2007) for more information on this issue.

\section{Data processing}

Collected data has to be processed to allow for control activity in precision livestock feeding. Mathematical modelling is a methodology used to understand and to quantify complex biological phenomena involved in animal production and can be the basis for data processing in precision livestock feeding control systems. A mathematical model is an equation or a set of equations 
representing the behaviour of the system (Thornley and France, 2006). Computer simulation, in its broadest sense, is described as the process of defining a mathematical-logical model for the real system and experimenting with this model on a computer (Pritsker, 1986; Thornley and France, 2006). By definition, models are a simplification of the system they represent, but the most relevant factors implicated in the animal responses that are to be controlled in precision livestock feeding need to be represented into the model. Mathematical models developed for precision livestock feeding, however, have to be designed to operate in real-time using real-time system measurements and, therefore, they are structurally different from traditional nutrition models, which are developed to work in a retrospective manner to simulate and understand known production situations. The basic principles for model development have to be reviewed because not all the models are adequate for precision livestock feeding and a model structure has to be chosen according to the available information and the desired control design of the system.

Mathematical models can take many different forms depending on model objectives and structure. Indeed, models can be empirical or mechanistic, deterministic or stochastic, static or dynamic, and real-time or prospective. Information about the development of mathematical models in animal science can be found elsewhere (Thornley and France, 2006). Different approaches have been used to predict animal growth (van Milgen et al., 2012). The earliest and still very common approach is empirical in which growth is described by a single or few mathematical equations. Empirical models use a black-box approach and are developed to describe the responses of a system without a description of the system itself and unconstrained by biological principles (Thornley and France, 2006). The empirical approach can provide effective prediction in a narrow range of situations related to experimental conditions under which the data were collected. However, the empirical approach fails to extrapolate results in situations beyond those used in the original experimental conditions. Because model parameters and structure do not have a biological meaning, these models need to be fitted with appropriate data to simulate each situation. Therefore, to ensure flexibility and to allow effective prediction in a wide range of situations, models with mechanistic (deductive) components are preferred (Baldwin, 1976; Whittemore, 1986). Mechanistic models provide some degree of understanding of the biological phenomena implicated in the response of the system (Thornley and France, 2006). Mechanistic mathematical models have been the preferred approach in animal sciences since the 70s when protein and lipid deposition (and the resulting body weight gain) was modelled from the nutrient supply (Whittemore and Fawcett, 1976). This and other early models have inspired the development of other nutritional models simulating growth in pigs (Black et al., 1986; Moughan et al., 1987; Pomar et al., 1991; Birkett and de Lange, 2001; Green and Whittemore, 2003; Halas et al., 2004; van Milgen et al., 2008), poultry (Emmans, 1981; Emmans, 1988; Hancock et al., 1995; Gous et al., 1999), turkeys (Hurwitz et al., 1991; Rivera-Torres et al., 2011), conceptus growth and milk production in sows (Dourmad et al., 2008; NRC, 2012) and egg production in hens (Fisher et al., 1973).

Mathematical models can be deterministic or stochastic. Deterministic models make a unique prediction for each specific set of input variables without any associated probability distribution. Stochastic models contain random elements in the model, so that, in addition to predicting the expected value of a performance trait, they also predict its dispersion (Thornley and France, 2006). Variation is essential and inherent to living systems and variation among the animals significantly contributes to the efficiency with which nutrients can be used (Curnow, 1973) independently of genetic variation (Knap, 2000; Knap and Jorgensen, 2000; Pomar et al., 2003; Brossard et al., 2009; Vautier et al., 2013), and environmental or animal management aspects 
(Wellock et al., 2004). This variation is essential for the understanding of the biological mechanisms implicated in the response of populations to the nutrient intake, given that the response of a population to treatments differs in magnitude and shape from that of an individual animal (Pomar et al., 2003). Mathematical models designed to estimate nutrient requirements and responses in a population of animals need to account for individual variation.

Static models do not contain time as a driving variable and do not make time-dependent predictions. Dynamic models are developed to quantify and to study the evolution of a system over time (Thornley and France, 2006). Essential elements of dynamic models are the differential equations in which time is an independent variable driving the rate of change of the state variables of the system. Most models in animal science and specifically in swine nutrition are dynamic because of the animal responses and requirements change over time.

The utilization of mechanistic models in precision livestock feeding systems has been criticized because these models are overly complex and the information required by the model to simulate practical conditions is not always available (Aerts et al., 2003; Wathes et al., 2008). On the other hand, the simplicity of empirical models is counteracted by the difficulty to represent interactions between nutrients and animals. Despite the fundamental structural differences between empirical and mechanistic models in the way they predict the response of the animal to the nutrient supply, both types of models have to be calibrated a priori using data collected from reference populations (Pomar et al., 2015) in which the phenotypic performance potential of the animal is quantified. Indeed, mechanistic growth models for pigs use intrinsic characteristics of a reference population either to describe the potential (phenotypic) protein deposition and feed intake patterns (Dourmad et al., 2008; van Milgen et al., 2008; NRC, 2012) or potential body protein and lipid deposition (Emmans, 1981; Black et al., 1986) while empirical models have the animal responses embedded into the model. To be used in precision livestock feeding, empirical and mechanistic models are, therefore, challenged by the difficulty of identifying the right reference population for its calibration, the fact that actual populations and individual animals may follow feed intake and growth patterns different than the ones observed in the reference population (Pomar et al., 2015).

The computational power and reliability of modern information technologies empower the utilization of advanced recursive technologies in the development of PLF and precision livestock feeding applications (Wathes et al., 2008). These modelling techniques (e.g., artificial neural networks) estimate unknown model parameters of an abstract mathematical model, based on online input and output measurements. Model parameters are estimated on-line during the process, resulting in a model that continuously adapts its response to on-line process inputs and outputs. There are few examples in which these models have been used in PLF or precision livestock feeding applications (Korthals et al., 1994; Bridges et al., 1995; Aerts et al., 2000; Thomson and Smith, 2000). The limitation of using the recursive approach in precision livestock feeding is related to the fact that model parameters and model structure do not provide biological insight in the causal mechanisms implicated in animal responses, that animal response and input parameters may have unsymmetrical variation, and that the animal responses to input variation does not evolve in the same timeframe. For example, when animal processes are modelled for which there is a significant time lag between the effects of varying input parameters (e.g., dietary lysine intake) and the response (e.g., body weight gain and composition), the autocalibration capability of these recursive models is limited and they will generate irregular control signals (Cangar et al., 2008). Rapid animal responses such as a behavioural response to inputs such as temperature and light intensity may be easily controlled by recursive models in PLF applications (Aerts et al., 2000). 
The disadvantages associated with black-box models can be overcome by using an intermediate approach of grey-box models in which recursive technologies and mechanistic models are combined. This approach was suggested by Bridges et al. (1995) who used a mechanistic swine growth model to generate physiological response data and this response data were then used to train and validate three backward propagation neural network models describing the effect of the environment on average daily gain, feed intake, heat production, and physiological status of the animal. The authors concluded that neural network models can be used to simplify data extraction from complex models and be used in instances where the use of the full model is difficult or impossible. Another grey-box model application was proposed by Hauschild et al. (2012), who combined black-box (i.e., empirical) and "knowledge-based" (i.e., mechanistic) model components to estimate daily amino acid requirements in individual growing-finishing pigs. The empirical component of this model estimated daily feed intake, body weight, and daily gain based on individual information collected in real time. Based on these daily estimations, the mechanistic model component predicted the concentration of amino acids required to meet the daily growth needs. The principles behind this model approach have been described (Hauschild et al., 2010; Pomar et al., 2015) and validated (Andretta et al., 2014; Andretta et al., 2016b).

\section{Control of the system}

The main objective of precision livestock feeding is to monitor, manage, and control animal feeding and nutrition continuously and automatically. Data collection and monitoring devices provide the farmer with detailed information about the animal's actual conditions and performance, the utilization of farm resources, while data processing helps with system surveillance (e.g., disease detection) and the estimation of optimal production strategies (e.g., optimal slaughter and production strategies). This information can also be used by an automatic controller to make decisions, which in the context of precision livestock feeding, will typically be the amount and the composition of the feed to be given to an individual or to a group of animals. Depending on the production objectives, the controller can be programmed to maximize growth rate, to minimize feed cost, to minimize nutrient excretion, or to meet another objective.

The determination of nutrient requirements and the control of the nutrient intake through feed composition and intake are two essential elements of precision livestock feeding. For a given animal and at a given time during his life, daily nutrient requirements can be estimated by the sum of the requirements for maintenance and production. These requirements are estimated for each nutrient taking into account the efficiency with which each nutrient is used. For a given animal, maintenance and production requirements change over time and so do nutrient requirements (NRC, 2012). Farm animals are often raised and fed in groups although, within a group, animals differ in feed intake and growth potential. Consequently, nutrient requirements vary among animals (Pomar et al., 2003; Wellock et al., 2004; Brossard et al., 2009). The dynamic and the between-animal variation are the two main sources of variation in nutrient requirements that can be controlled in precision livestock feeding systems. Production systems in which animals are fed individually can be used to control both sources of variation while in group-fed systems only the time-dependent variation can be controlled.

Therefore, several potential control strategies are available for the application of precision livestock feeding in commercial conditions. In feeding systems where animals are offered with feed ad libitum, the only way to control the nutrient intake is by varying the composition of the distributed feed. In ad libitum group-fed systems, animals can be fed for maximal production by providing nutrients following the time-dependent nutrient requirements of the group or for a given 
production strategy (i.e., body composition, population uniformity), by controlling the composition of the served feed. When animals are individually fed and offered feed ad libitum, both the between animal and the time-dependent nutrient requirements variation can be controlled. In feeding systems where animals are offered feed restrictively, the amount and the composition of the feed can be controlled. Maximum growth rate will not be attained in this situation although feeding strategies can be established to account for between animal and the time-dependent variation in nutrient requirements. For example, feed restriction in pregnant sows allows controlling body weight gain and fatness while maintaining conceptus growth. Examples of these control approaches for growing animals will be given in the following section.

\section{The implementation of precision livestock feeding principles in growing and finishing pig production systems}

Conventional growing and finishing pig feeding programs are designed to maximize population body weight gain, optimize carcass fatness, etc., and they provide a single feed to all the pigs in the pen or herd within each feeding phase. One to four-phase feeding systems are nowadays popular in commercial growing-finishing pig operations (Niemi et al., 2010; NRC, 2012) but it is acknowledged that increasing the number of feeding phases reduces feed costs, improves feed efficiency, and decreases nutrient excretion (Letourneau Montminy et al., 2005; Brossard et al., 2010). Multi-phase group-feeding systems allow the adjustment of the feed composition over time to better match the population nutrient requirements. Moving from conventional feeding systems to precision livestock feeding systems requires not only to increase the number of feeding phases, but also using the information concerning the actual status and evolution of the animal (e.g., feed intake, body weight, body composition) to control feed supply.

Accurate and automatic measurement of the amount of feed consumed daily by individuals or groups of pigs is an essential information element required for the implementation of precision livestock feeding in growing and finishing pig operations. Although liquid feeding systems provide predetermined amounts of feeds to pens, they are of limited use to provide information on the feed intake because feed is provided at restricted levels with these systems. The availability of commercial devices for measuring dry feed intake is still limited and seldom used for the implementation of precision livestock feeding in commercial piggeries. An individual feed intake recording system has been developed in the UK for the real-time control of growth (Parsons et al., 2007). The system is able to weigh the feed delivered to each pig at each visit. Similar precision livestock feeding system has been developed by Pomar et al. (2014) using an automated recording system (IVOG system, Insentec B.V., Marknesse, the Netherlands). Another example of dry feeders measuring the consumed feed has been developed in Australia (Banhazi et al., 2009; Banhazi et al., 2012a). This device can accurately measure the amount of feed supplied through the feed line (by an innovative feed sensor), estimating the amount of feed delivered to each feeder. Finally, an automatic and intelligent precision feeder (AIPF) developed for precision feeding of growing-finishing pigs has been developed (Pomar et al., 2011), which is able to provide a specific quantity and composition of feed to individual pigs at each feeder visit. The functioning of these AIPF feeders has been described elsewhere (Pomar et al., 2011; Pomar et al., 2015) and the feeders have been used in several research projects (Andretta et al., 2014; Cloutier et al., 2015; Andretta et al., 2016a).

Accurate and regular body weight measurements performed without causing stress and requiring labour input is a great asset for the implementation of precision livestock feeding in growing-finishing pig facilities. Available technologies for automatic animal weighing include 
conventional load cell platforms (Turner et al., 1985) and the combination of video cameras and image analysis. The possibility of estimating the weight of a pig from specific areas and dimensions through digital image analysis has been developed (Schofield, 1990; Brandl and Jørgensen, 1996; Whittemore and Schofield, 2000; Doeschl-Wilson et al., 2004; White et al., 2004a) and used in several experiments.

Lean growth is the major determinant of amino acid requirements in growing animals. Modern pigs are capable of maintaining high levels of lean deposition at heavier live weights. Measuring backfat and muscle thickness can be precious information to estimate body fat and protein. Although different technologies are available, ultrasound is without doubt the most widely used because of its cost, reliability, and portability (Moeller, 2002). However, it is still a manual operation and although automatic measurement methods of backfat thickness have been proposed (Tillett et al., 2002; Frost et al., 2004), these technologies have not been developed further since then.

After measuring the essential information concerning the feeds and animals, precision livestock feeding requires to determine optimal nutrient concentration of feeds to automatically provide animals with the amount and composition of the feed according to the established production objectives. Precision nutrition can be used in pig growing facilities to either allow pigs perform at their maximal growth potential or drive growth rate and body composition by restricting feed or nutrient intake. Actual pig growth models (e.g., van Milgen et al., 2008; NRC, 2012) have been developed to operate in a retrospective manner and are calibrated after all growth data have been collected to simulate the production situation. These models are designed to predict, under specific situations, the consequences of feed and nutrient intake in terms of animal responses (e.g., protein and lipid deposition, body weight growth). These models are used to evaluate the nutrient utilization by the animal and to test nutritional strategies. Mathematical models developed to be used in precision livestock feeding systems need to operate in real-time using appropriate realtime animal information (e.g., body weight and composition), behaviour (e.g., feed intake), environment (e.g., ambient temperature), health (e.g., body temperature, sounds to detect health status), and other parameters. When these models are conceived to achieve the animals' full growth potential, they can be devoid of feedback control elements and provide predictions based on actual and recent animal information. The objective of this real-time model-control approach is not to manipulate the animal response (i.e., body weight gain or composition) but to deliver the controlled production factors (e.g., feed composition) at the levels required for maximum growth.

Automatic blenders, feeders and feed, and animal management devices are required to apply the controller decisions. The development of feeding systems that allow blend-feeding and the automatic distribution of two or more feeds that, when combined in variable ratios, can meet the requirements of pigs throughout their growing period (Feddes et al., 2000; Pomar et al., 2014) makes the phase-feeding technique cost-effective. The feeds can be complete diets formulated to satisfy the requirements of pigs at the beginning and at the end of their growing period or to contain complementary amounts of nutrients in such a way that when blended, the feeds become complete diets (Joannopoulos et al., 2015). Blending two feeds may be seen as a promising option for feed companies, since it means that there are just two feeds to prepare, with only the proportions changing between the feeding phases and between farms. These group and individual feeding precision livestock feeding systems will benefit from using accurate and individual feed intake and body weight measurements to drive the amount and composition of the feeds to be served to the pigs. 
To further develop precision livestock feeding systems, it is necessary to improve our actual understanding of several animal metabolic processes. Precision livestock feeding is still based on models and nutritional concepts of average population responses. When feeding individual pigs with daily tailored diets, these traditional nutritional concepts seem insufficient (Remus, 2015; Ghimire et al., 2016; Remus et al., 2017). It is necessary to distinguish the nutritional requirements of a population from those of an individual. Individual pigs are able to modulate growth and the composition of growth according to the level of available amino acids (Remus, 2018). Also, pigs can respond differently to the same amount of ingested amino acid, due to differences in the efficiency of amino acid utilization. These aspects are not considered in current nutritional models, which assume that the efficiency by which animals use the available amino acids is constant. Similarly, the amino acid composition of whole body protein is assumed to be constant as well, while it has been shown that it can vary. Similar results have been found for the efficiency of calcium and phosphorus utilization (Gonzalo et al., 2018). Understanding the metabolic processes responsible for the observed variation between individual animals in their ability to use dietary nutrients is challenging nutritionists and modellers but is required to further improve the efficiency of livestock production. Advances in precision livestock feeding rely on the development of sound nutritional concepts and comprehensive biological models developed to more precisely estimate individual nutrient requirements in real-time.

\section{PLF and precision livestock feeding systems used in practice}

The real-time modelling-control approach was used by Pomar et al. (2014) to control the timedependent variation of group-housed pigs offered feed ad libitum. Feed intake was measured daily with an automatic device and animals were weighed manually every two weeks. The desired diet composition was obtained by blending two feeds with a high and a low nutrient concentration. Nutrient requirements of the group were estimated each day based on body protein and growth rates observed in animals of similar genetic background. Comparing the traditional three-phase feeding system to the daily-phase feeding system, the authors concluded that protein intake could be reduced by $7 \%$ while nitrogen excretion was reduced by $12 \%$.

Controlling the time-dependent and the among-animal variation can further help reducing nutrient intake and excretion. This modelling approach was used to estimate nutrient requirements in real-time in individual pigs (Hauschild et al., 2012; Pomar et al., 2015) and applied to feed pigs individually with daily tailored diets (Andretta et al., 2014). The latter authors showed that daily adjustment of the diet resulted in a $27 \%$ reduction in total lysine intake, without affecting growth. This additional $20 \%$ reduction in lysine intake in relation to group-fed pigs could be obtained by feeding the animals individually and thus controlling simultaneously the time-dependent and the between-animal variation. Although reducing feed cost depends to a great extent on feed prices, it is expected that feed cost can be reduced by 1-3\% when only controlling the time-dependent variation while a $8-10 \%$ reduction can be obtained when controlling also the among-animal variation.

Restricting feed or nutrient intake has been proposed in several precision livestock feeding systems with the objective to minimize feed cost, ammonia emissions, or to maximize the return per pig space. Demmers et al. (2012) used an automated feeding system to provide the desired amount of feed of fixed composition to each pen. Daily body weight was estimated using a commercial visual image analysis system. The controller was based on a recursive neural network of growth and ammonia emission models, which were calibrated from previous experiments. The system was used to control the amount of feed delivered to pens and the ambient temperature to 
optimize growth and reduce ammonia emissions. A precision livestock feeding system was also used by Niemi et al. (2010) to study multi-phase and two phases feeding systems and growth patterns in terms of economic return per pig space. In this multi-phase feeding system, the amount of feed, the protein concentration in the diet, and the time to reach slaughter weight were optimized on a daily basis. The controller included a stochastic dynamic model that estimated nutrient requirements as a function of body weight and evaluated the different scenarios to maximize the return on capital investment. The authors concluded that producers would benefit from adjusting diet composition on a daily basis but that the optimal production strategy and the return on investment are affected by the variation among pigs and the variation in feed and carcass prices.

A real-time system for the integrated control of population pig growth and pollutant emissions was also proposed (Whittemore et al., 2001; Parsons et al., 2007) using an automatic daily feed intake recording device and a visual image analysis system to estimate daily body weight (Schofield et al., 1999; White et al., 2004b). Pigs were fed ad libitum in this precision livestock feeding system with diets varying in crude protein concentration. A high and a low-protein diets were manually blended to obtain the desired level of protein in the final mix to be served. The authors concluded that weight gain in pigs can be controlled through the proposed ad libitum feeding precision livestock feeding system and that some control of body fatness may also be possible.

\section{Factors that can influence the successful application of precision livestock feeding systems on farms}

Precision livestock feeding can be considered as a component of a PLF system and the successful on-farm application of precision livestock feeding systems will face similar challenges as other PLF systems. Wathes et al. (2008) considered PLF as an "embryonic technology with great promise" but they also acknowledged that few PLF have been implemented successfully so far. In addition, there may be a long time path between development and application. For example, the milking robot was developed in the 80 s and has been commercialized since the early 90s but, despite 25 years of availability, it has yet to revolutionize the dairy industry. In an article with the provocative title "Is precision livestock farming an engineer's daydream or nightmare, an animal's friend or foe, and a farmer's panacea or pitfall?", Wathes et al. (2008) discussed the development and adoption of PLF systems. Others (Groot Koerkamp et al., 2007; Banhazi et al., 2012a; Banhazi et al., 2012b) have expanded on these ideas and the main issues in the development and successful adoption of PLF (and thus precision livestock feeding) can be summarized as follows:

- There is a strong need for coordination and to involve different experts and stakeholders in the development and implementation of PLF (i.e., researchers, engineers, technology suppliers, economists, farmers, consumers, and citizens).

- With the rapid development and available of sensors, more focus should be paid to data interpretation and control mechanisms.

- Not all processes need to be automated; it is about assisting farmers, not about automatic farms. Groot Koerkamp et al. (2007) argued that there is not necessarily an intrinsic connection between (better) measurements and (better) control and that the allocation of controlling power is an important factor to consider. Who is in control: a machine, the farmer, the animal? Groot Koerkamp et al. (2007) suggested that recursive control by animals may be an alternative means to create order in complex biological systems, which, to some extent, can be interpreted as the consideration of agro-ecological principles in PLF. 
- The benefits of PLF systems should be verified on the farm.

- Appropriate deployment of PLF systems and training, service and support for farmers should be assured. The latter may imply the development of a new service industry. As indicated by Banhazi et al. (2012b), farmers are biologists by nature and only technologists occasionally. Although they do invest in technology, it is typical machinery that they look forward to buying as opposed to software, sensors or services.

- Awareness and education for consumers and citizens. Citizens may perceive PLF as a further industrialization of livestock production. Education should help appreciating controlled, animal-centric livestock production, while looking for attributes that make modern production better for the animal and more sustainable. Food production should be made more transparent. For example, the EU-funded BrightAnimal project suggested using social networks, FarmCams, and a "Be a farmer for a day" initiative to improve awareness.

Some of these issues addressed above have been considered in projects funded by EU-funded projects such as EU-PLF (www.eu-plf.eu), ALL-SMART-PIGS (www.all-smart-pigs.com/), and Feed -a-Gene (www.feed-a-gene.eu).

An increasing concern is the adaptability and training required by farmers to use PLF systems. Some authors (Van Hertem et al., 2017) believe that use of appropriate data visualization tools can facilitate the farmer acceptance and adoption of PLF applications. These authors tested and evaluated PLF systems on ten fattening pig farms and five broiler farms. Data of production, climate and behaviour was continuously measured, analyzed daily and made available on a webbased tool. Nearly $50 \%$ of the farmers took the training, but only $28 \%$ of the trained farmers actively used the tool. According to the authors, the success of the training seemed to be dependent on the complexity of the system installed on the farm (e.g., environmental sensors) and the training/education of the end user. They conclude that training is fundamental for the adoption of such systems.

\section{Future perspectives}

As indicated above, different technologies are now available for real-time and individual phenotyping and the availability of feeder equipment allows the distribution of specific diets to individual animals. An important issue that needs to be addressed further in the future is the control of the system, and how precision livestock feeding can and should interact with other components of PLF and with livestock production in general. For example, precision livestock feeding allows having large groups of pigs in a single pen, but this raises questions on how the group size affects animal behaviour and health, on pen design, and on management of animals in the pen. In recent years, some growing-finishing pig facilities are moving to larger groups of up to 1,000 pigs/pen. These facilities are generally equipped with auto-sorting systems that weigh individual animals before entering the feed court, identifying pigs that reach market weight, and sort them into a loading pen (Street and Gonyou, 2008). The development of nutritional concepts and models specially designed for precision livestock feeding and the system integration, to provide early alerts about changes in the system (e.g. health status based on a reduction in the feed intake) seem to be of great importance. These issues need to be addressed in the future if precision livestock feeding is to go beyond being an alternative feeding technique based on the optimization of the nutrient supply to the animal. Precision livestock feeding has the potential to be an important element of innovative livestock production systems, which may involve changes in several processes and elements within the system (Groot Koerkamp et al., 2007). 


\section{References}

Aerts, J. M., D. Berckmans, P. Saevels, E. Decuypere, and J. Buyse. 2000. Modelling the static and dynamic responses of total heat production of broiler chickens to step changes in air temperature and light intensity. Br. Poult. Sci. 41(5):651-659. doi: 10.1080/713654981

Aerts, J. M., C. M. Wathes, and D. Berckmans. 2003. Dynamic Data-based Modelling of Heat Production and Growth of Broiler Chickens: Development of an Integrated Management System. Biosys. Eng. 84(3):257-266. doi: http://dx.doi.org/10.1016/S1537-5110(02)00285-4

Andretta, I., C. Pomar, M. Kipper, L. Hauschild, and J. Rivest. 2016a. Feeding behavior of growingfinishing pigs reared under precision feeding strategies. Journal of Animal Science 94(7):30423050.

Andretta, I., C. Pomar, J. Rivest, J. Pomar, P. A. Lovatto, and J. R. Neto. 2014. The impact of feeding growing-finishing pigs with daily tailored diets using precision feeding techniques on animal performance, nutrient utilization, and body and carcass composition. J. Anim. Sci. 92:3925-3936. doi: 10.2527/jas.2014-7643

Andretta, I., C. Pomar, J. Rivest, J. Pomar, and J. Radünz. 2016b. Precision feeding can significantly reduce lysine intake and nitrogen excretion without compromising the performance of growing pigs. animal:1-11.

Baldwin, R. L. 1976. Principles of modelling animal systems. Proc. New Zealand Soc. Anim. Prod 36:128139.

Banhazi, T. M., L. Babinszky, V. Halas, and M. Tscharke. 2012a. Precision Livestock Farming: Precision feeding technologies and sustainable livestock production. International Journal of Agricultural and Biological Engineering 5(4):54-61.

Banhazi, T. M., H. Lehr, J. L. Black, H. Crabtree, P. Schofield, M. Tscharke, and D. Berckmans. 2012b. Precision Livestock Farming: An international review of scientific and commercial aspects. International Journal of Agricultural and Biological Engineering 5(3):1-9.

Banhazi, T. M., D. L. Rutley, B. Parking, and B. M. Lewis. 2009. Field Evaluation of a Prototype Sensor for Measuring Feed Disappearance in Livestock Buildings. Australian Journal of Multi-disciplinary Engineering 7(1):27-38.

Batterham, E. S., L. M. Andersen, D. R. Baigent, R. E. Darnell, and M. R. Taverner. 1990. A comparison of the availability and ileal digestibility of lysine in cottonseed and soya-bean meals for grower/finisher pigs. British Journal of Nutrition 64(03):663-677. doi: doi:10.1079/BJN19900069

Berckmans, D. 2004. Automatic on-line monitoring of animals by precision livestock farming. In: ISAH Conference on Animal Production in Europe: The Way Forward in a Changing World, Saint-Malo, France. p 27-31.

Birkett, S., and C. F. M. de Lange. 2001. A computational framework for a nutrient flow representation of energy utilization by growing monogastric animals. Br. J. Nutr. 86:661-674.

Black, J. L. 2007. J.M. Bell Memorial Lecture: Role of research in advancing animal agriculture in the 21st century. Proceedings of the Western Nutrition Conference, September 25-27, 2007, Sheraton Cavalier Hotel Saskatoon. p 71-80. University of Saskatchewan, Saskatoon, Canada.

Black, J. L., R. G. Campbell, I. H. Williams, K. J. James, and G. T. Davies. 1986. Simulation of energy and amino acid utilisation in the pig. Res. Dev. Agric. 3(3):121-145.

Black, J. L., and L. Scott. 2002. More beef from pastures: current knowledge, adoption and research opportunities, Meat and Livestock Australia Limited, Sydney, Australia.

Brandl, N., and E. Jørgensen. 1996. Determination of live weight of pigs from dimensions measured using image analysis. Comput. Electron. Agric. 15(1):57-72. doi: http://dx.doi.org/10.1016/01681699(96)00003-8 
Bridges, T. C., R. S. Gates, K. L. Chao, L. W. Turner, and H. Minagawa. 1995. Techniques for development of swine performance response surfaces. Transactions of the American Society of Agricultural Engineers 38(5):1505-1511.

Brossard, L., J.-Y. Dourmad, J. Rivest, and J. van Milgen. 2009. Modelling the variation in performance of a population of growing pig as affected by lysine supply and feeding strategy. Animal 3(1):11141123. doi: doi:10.1017/S1751731109004546

Brossard, L., N. Quiniou, J. Y. Dourmad, Y. Salaün, and J. Van Milgen. 2010. Définir des stratégies alimentaires alliant performance économique et impact environnemental grâce à la modélisation du groupe de porcs en croissance. Journ. Rech. Porcine 42:131-132.

Cangar, Ö., J. M. Aerts, E. Vranken, and D. Berckmans. 2008. Effects of different target trajectories on the broiler performance in growth control. Poult. Sci. 87(11):2196-2207.

Cloutier, L., C. Pomar, M. P. Letourneau Montminy, J. F. Bernier, and J. Pomar. 2015. Evaluation of a method estimating real-time individual lysine requirements in two lines of growing-finishing pigs. Animal 9(4):561-568. doi: 10.1017/S1751731114003073

Curnow, R. N. 1973. A smooth population response curve based on an abrupt threshold and plateau model for individuals. Biometrics 29:1-10.

Demmers, T. G. M., S. Gauss, C. M. Wathes, Y. Cao, and C. M. Parsons. 2012. Simultaneous Monitoring and Control of Pig Growth and Ammonia Emissions Ninth International Livestock Environment Symposium, Sponsored by ASABE, Valencia Conference Centre, Valencia, Spain, July 8 - 12, 2012

Doeschl-Wilson, A. B., D. M. Green, C. T. Whittemore, C. P. Schofield, A. V. Fisher, and P. W. Knap. 2004. The relationship between the body shape of living pigs and their carcass morphology and composition. Anim. Sci. 79:73-83.

Dourmad, J. Y., M. Etienne, A. Valancogne, S. Dubois, J. v. Milgen, and J. Noblet. 2008. InraPorc: a model and decision support tool for the nutrition of sows. (Special Issue: Mathematical models that predict the effects of feed characteristics on animal performance. Anim. Feed Sci. Technol. 143(1/4):372-386.

Dourmad, J. Y., B. Seve, P. Latimier, S. Boisen, J. Fernandez, C. van der Peet-Schwering, and A. W. Jongbloed. 1999. Nitrogen consumption, utilisation and losses in pig production in France, The Netherlands and Denmark. Livest. Prod. Sci. 58(3):261-264.

Emmans, G. C. 1981. A model of the growth and feed intake of ad libitum fed animals, particularely poultry. In: G. M. Hillyer, C. T. Whittemore and R. G. Gunn, editors, Computers in Animal Production. The British Society of Animal Production-Occasional publication No 5. Thames Ditton, Surrey, England. p. 103-110.

Emmans, G. C. 1988. Genetic components of potential and actual growth. In: R. B. Land, G. Bulfield and W. G. Hill, editors, Animal Breeding Opportunities. The British Society of Animal ProductionOccasional publication No 12. Midlothian, Scotland, UK. p. 153-181.

Feddes, J. J. R., C. A. Ouellette, and J. J. Leonard. 2000. A system for providing protein for pigs in intermediately sized grower/finisher barns. Canadian Agricultural Engineering 42(4):209-213.

Fisher, C., T. R. Morris, and R. C. Jennings. 1973. A model for the description and prediction of the response of laying hens to amino acid intake. Br. Poult. Sci. 14:469-484.

Frost, A. R., A. P. French, R. D. Tillett, T. P. Pridmore, and S. K. Welch. 2004. A vision guided robot for tracking a live, loosely constrained pig. Comput. Electron. Agric. 44(2):93-106. doi: http://dx.doi.org/10.1016/j.compag.2004.03.003

Ghimire, S., C. Pomar, and A. Remus. 2016. Variation in protein content and efficiency of lysine utilisation in growing-finishing pigs. Energy and protein metabolism and nutrition:351-352. doi: 10.3920/978-90-8686-832-2

Gonzalo, E., M. P. Létourneau-Montminy, A. Narcy, J. F. Bernier, and C. Pomar. 2018. Consequences of dietary calcium and phosphorus depletion and repletion feeding sequences on growth 
performance and body composition of growing pigs. animal 12(6):1165-1173. doi: $10.1017 / \mathrm{S} 1751731117002567$

Gous, R. M., E. T. J. Moran, H. R. Stilborn, G. D. Bradford, and G. C. Emmans. 1999. Evaluation of parameters needed to describe the overall growth, the chemical growth and the growth of feathers and breast muscles in broilers. Poult. Sci. 78:812-821.

Green, D. M., and C. T. Whittemore. 2003. Architecture of a harmonized model of the growing pig for the determination of dietary net energy and protein requirements and of excretions into the environment (IMS Pig). Anim. Sci. 77(1):113-130.

Groot Koerkamp, P. W. G., A. P. Bos, and E. J. van Henten. 2007. Precision Livestock farming: creating order beyond control. In: S. Cox, editor, 3rd International Congress on Precision Livestock Farming, Skiathos, Greece, 3-7 June 2007. - Skiathos, 2007. Wageningen Academic Publishers, Wageningen, the Netherlands. p. 17-26.

Halas, V., J. Dijkstra, L. Babinszky, M. Verstegen, and W. J. J. Gerrits. 2004. Modelling of nutrient partitioning in growing pigs to predict their anatomical body composition. 1. Model description. Br. J. Nutr. 92:707-723.

Hancock, C. E., G. D. Bradford, G. C. Emmans, and R. M. Gous. 1995. The evaluation of the growth parameters of six strains of commercial broiler chickens. Br. Poult. Sci. 36(2):247-264. doi: 10.1080/00071669508417773

Hauschild, L., P. A. Lovatto, J. Pomar, and C. Pomar. 2012. Development of sustainable precision farming systems for swine: Estimating real-time individual amino acid requirements in growing-finishing pigs. J. Anim. Sci. 90(7):2255-2263. doi: 10.2527/jas.2011-4252

Hauschild, L., C. Pomar, and P. A. Lovatto. 2010. Systematic comparison of the empirical and factorial methods used to estimate the nutrient requirements of growing pigs. animal 4(05):714-723. doi: doi:10.1017/S1751731109991546

Heger, J., and Z. Frydrych. 1985. Efficiency of utilization of essential amino acids in growing rats at different levels of intake. British Journal of Nutrition 54(02):499-508. doi: doi:10.1079/BJN19850135

Hurwitz, S., H. Talpaz, I. Bartov, and I. Plavnik. 1991. Characterization of Growth and Development of Male British United Turkeys. Poult. Sci. 70(12):2419-2424. doi: 10.3382/ps.0702419

Joannopoulos, E., F. Dubeau, J.-P. Dussault, and C. Pomar. 2015. The diet problem. In: L. M. PlàAragonés, editor, Handbook of Operational Research in Agriculture and the Agri-Food Industry. Springer, City. p. 397-417.

Knap, P. W. 2000. Stochastic simulation of growth in pigs: relations between body composition and maintenance requirements as mediated through protein turn-over and thermoregulation. Anim. Sci. 71:11-30.

Knap, P. W., and H. Jorgensen. 2000. Animal-intrinsic variation in the partitioning of body protein and lipid in growing pigs. Anim. Sci. 70:29-37.

Korthals, R. L., G. L. Hahn, and J. A. Nienaber. 1994. Evaluation of Neural Networks as a Tool for Management of Swine Environments. Transactions of the ASABE 37(4)doi: doi: 10.13031/2013.28210

Letourneau Montminy, M.-P., C. Boucher, C. Pomar, F. Dubeau, and J.-P. Dussault. 2005. Impact de la méthode de formulation et du nombre de phases d'alimentation sur le coût d'alimentation et les rejets d'azote et de phosphore chez le porc charcutier. Journ. Rech. Porcine 37:25-32.

Moeller, S. J. 2002. Evolution and use of ultrasonic technology in the swine industry. J. Anim. Sci. 80(ESuppl 2):E19-E27.

Mohn, S., A. M. Gillis, P. J. Moughan, and C. F. de Lange. 2000. Influence of dietary lysine and energy intakes on body protein deposition and lysine utilization in the growing pig. J. Anim. Sci. 78(6):1510-1519. 
Moughan, P. J. 1989. Simulation of the daily partitioning of lysine in the $50 \mathrm{~kg}$ liveweight pig - A factorial approach to estimating amino acid requirements for the growth and maintenence. Res. Dev. Agric. 6:7-14.

Moughan, P. J., W. C. Smith, and G. Pearson. 1987. Description and validation of a model simulating growth in the pig (20-90 kg liveweight). N. Z. J. Agric. Res. 30:481-490.

Niemi, J. K., M.-L. Sevón-Aimonen, K. Pietola, and K. J. Stalder. 2010. The value of precision feeding technologies for grow-finish swine. Livest. Sci. 129(1-3):13-23. doi: DOI: 10.1016/j.livsci.2009.12.006

NRC. 2012. Nutrient Requirements of Swine. 11th ed. National Academy Press, Washington, DC.

Parsons, D. J., D. M. Green, C. P. Schofield, and C. T. Whittemore. 2007. Real-time Control of Pig Growth through an Integrated Management System. Biosys. Eng. 96(2):257-266.

Patience, J. F. 1996. Precision in swine feeding programs: An integrated approach. Animal Feed Science and Technology 59(1-3):137-145. doi: http://dx.doi.org/10.1016/0377-8401(95)00894-2

Pomar, C., D. L. Harris, and F. Minvielle. 1991. Computer-simulation model of swine production systems. 1. Modeling the growth of young-pigs. J. Anim. Sci. 69:1468-1488.

Pomar, C., L. Hauschild, G. H. Zhang, J. Pomar, and P. A. Lovatto. 2009. Applying precision feeding techniques in growing-finishing pig operations. R. Bras. Zootec. 38 226-237 (Supl. special).

Pomar, C., L. Hauschild, G. H. Zhang, J. Pomar, and P. A. Lovatto. 2010. Precision feeding can significantly reduce feeding cost and nutrient excretion in growing animals. In: D. Sauvant, J. van Milgen, P. Faverdin and N. Friggens, editors, Modelling Nutrition Digestion and Utilization in Farm Animals. Wageningen Academic Publishers. p. 327-334.

Pomar, C., I. Kyriazakis, G. C. Emmans, and P. W. Knap. 2003. Modeling stochasticity: Dealing with populations rather than individual pigs. J. Anim. Sci. 81 (E. Suppl. 2):E178-E186.

Pomar, C., J. Pomar, F. Dubeau, E. Joannopoulos, and J.-P. Dussault. 2014. The impact of daily multiphase feeding on animal performance, body composition, nitrogen and phosphorus excretions, and feed costs in growing-finishing pigs. animal 8(05):704-713. doi: doi:10.1017/S1751731114000408

Pomar, C., J. Pomar, J. Rivest, L. Cloutier, M. P. Letourneau-Montminy, I. Andretta, and L. Hauschild. 2015. Estimating real-time individual amino acid requirements in growing-finishing pigs : towards a new definition of nutrient requirements? In: N. K. Sakomura, R. Gous, I. Kyriazakis and L. Hauschild (eds.) Nutritional modelling for pigs and poultry. p 157-174. CAB International, Wallingford, UK.

Pomar, J., V. López, and C. Pomar. 2011. Agent-based simulation framework for virtual prototyping of advanced livestock precision feeding systems. Comput. Electron. Agric. 78(1):88-97. doi: 10.1016/j.compag.2011.06.004

Poulsen, H. D., A. W. Jongbloed, P. Latimier, and J. A. Fernandez. 1999. Phosphorus consumption, utilisation and losses in pig production in France, The Netherlands and Denmark. Livest. Prod. Sci. 58(3):251-259.

Pritsker, A. A. B. 1986. Introduction to simulation and SLAM II. Wiley, West Lafayette, IN.

Remus, A. 2015. Modelos para estimar exigências nutricionais de aminoácidos e resposta à ingestão de metionina: sistema tradicional por fases x nutrição de precisão. Master thesis, Universidade Estadual Paulista Júlio de Mesquita Filho, Faculdade de Ciências Agrárias e Veterinárias.

Remus, A. 2018. The ideal protein profile for growing-finishing pigs in precision feeding systems: threonine. Dual Doctoral Program, Université Laval, Québec, QC, Canada.

Remus, A., M. P. Létourneau Montminy, L. Hauschild, and C. Pomar. 2017. Pigs receiving daily tailored diets have different amino acid requirements than pigs raised in conventional phase feeding systems. Journal of Animal Science 95(supplement2):134-135. doi: 10.2527/asasmw.2017.279 
Rivera-Torres, V., P. R. Ferket, and D. Sauvant. 2011. Mechanistic modeling of turkey growth response to genotype and nutrition. J. Anim. Sci. 89(10):3170-3188. doi: 10.2527/jas.2010-3504

Schofield, C. P. 1990. Evaluation of image analysis as a means of estimating the weight of pigs. J . agric . Engng Res . 47(0):287-296. doi: http://dx.doi.org/10.1016/0021-8634(90)80048-Y

Schofield, C. P., J. A. Marchant, R. P. White, N. Brandl, and M. Wilson. 1999. Monitoring Pig Growth using a Prototype Imaging System. J . agric . Engng Res . 72(3):205-210. doi: http://dx.doi.org/10.1006/jaer.1998.0365

Sifri, M. 1997. Precision Nutrition for Poultry. The Journal of Applied Poultry Research 6(4):461. doi: 10.1093/japr/6.4.461

Street, B. R., and H. W. Gonyou. 2008. Effects of housing finishing pigs in two group sizes and at two floor space allocations on production, health, behavior, and physiological variables. J. Anim. Sci. 86(4):982-991. doi: 10.2527/jas.2007-0449

Thomson, S. J., and L. A. Smith. 2000. Feasibility of using neural networks for real-time prediction of poultry deep body temperature responses to stressful changes in ambient temperature. Appl. Eng. Agric. 16(3):303-308. doi: doi: 10.13031/2013.5139

Thornley, J. H. M., and J. France, editors. 2006. Mathematical Models in Agriculture. Quantitative Methods for the Plant, Animal and Ecological Sciences. CABI Publ., Wallingford, UK.

Tillett, R. D., A. R. Frost, and S. K. Welch. 2002. AP-Animal Production Technology: Predicting Sensor Placement Targets on Pigs using Image Analysis. Biosys. Eng. 81(4):453-463. doi: http://dx.doi.org/10.1006/bioe.2001.0018

Turner, M. J. B., J. A. Benson, M. Hanley, and E. S. Hartwell. 1985. Automatic weight monitoring of pigsPart 1: Trials of prototype weigh platforms National Institute of Agricultural Engineering Divisional Note DN 1266. p 46. National Institute of Agricultural Engineering, UK.

Van Hertem, T., L. Rooijakkers, D. Berckmans, A. Peña Fernández, T. Norton, D. Berckmans, and E. Vranken. 2017. Appropriate data visualisation is key to Precision Livestock Farming acceptance. Computers and Electronics in Agriculture 138:1-10. doi: https://doi.org/10.1016/j.compag.2017.04.003

Van Kempen, T. A. T. G., and P. H. Simmins. 1997. Near-Infrared Reflectance Spectroscopy in Precision Feed Formulation. The Journal of Applied Poultry Research 6(4):471-477. doi: 10.1093/japr/6.4.471

van Milgen, J., J. Noblet, J.-Y. Dourmad, E. Labussière, F. Garcia-Launay, and L. Brossard. 2012. Precision pork production: Predicting the impact of nutritional strategies on carcass quality. Meat Sci. 92(3):182-187. doi: 10.1016/j.meatsci.2012.03.019

van Milgen, J., A. Valancogne, S. Dubois, J.-Y. Dourmad, B. Seve, and J. Noblet. 2008. InraPorc: A model and decision support tool for the nutrition of growing pigs. Anim. Feed Sci. Technol. 143:387405.

Vautier, B., N. Quiniou, J. van Milgen, and L. Brossard. 2013. Accounting for variability among individual pigs in deterministic growth models. Animal 7(8):1265-1273. doi: 10.1017/\$1751731113000554

Vranken, E., and D. Berckmans. 2017. Precision livestock farming for pigs. Animal Frontiers 7(1):32-37. doi: 10.2527/af.2017.0106

Wathes, C. M., H. H. Kristensen, J. M. Aerts, and D. Berckmans. 2008. Is precision livestock farming an engineer's daydream or nightmare, an animal's friend or foe, and a farmer's panacea or pitfall? Comput. Electron. Agric. 64(1):2-10. doi: DOI: 10.1016/j.compag.2008.05.005

Wellock, I. J., G. C. Emmans, and I. Kyriazakis. 2004. Modeling the effects of stressors on the performance of populations of pigs. J. Anim. Sci. 82(8):2442-2450.

White, A. A., S. Nitzke, and K. E. Peterson. 2004a. Are soft drinks getting a bum rap? We don't think so. Journal of Nutrition Education and Behavior 36(5):266-271. (Journal Article) 
White, R. P., C. P. Schofield, D. M. Green, D. J. Parsons, and C. T. Whittemore. 2004b. The effectiveness of a visual image analysis (VIA) system for monitoring the performance of growing/finishing pigs. Anim. Sci. 78:409-418.

Whittemore, C. T. 1986. An approach to pig growth modeling. J. Anim. Sci. 63(2):615-621.

Whittemore, C. T., and R. H. Fawcett. 1976. Theoretical aspects of a flexible model to stimulate protein and lipid growth in pigs. Anim. Prod. 22(01):87-96. doi: doi:10.1017/S0003356100035455

Whittemore, C. T., D. M. Green, and C. P. Schofield. 2001. Nutrition management of growing pigs. In: C. M. Wathes, A. R. Frost, F. Gordon and J. D. Wood (eds.) Integrated Management Systems for Livestock. p 89-95. British Society of Animal Science.

Whittemore, C. T., and C. P. Schofield. 2000. A case for size and shape scaling for understanding nutrient use in breeding sows and growing pigs. Livest. Prod. Sci. 65(3):203-208. doi:

http://dx.doi.org/10.1016/S0301-6226(99)00136-0 